\title{
Morphological, Biochemical and Genotypic Analysis of Zoonotic Campylobacter jejuni Isolated from Chicken Meat Samples
}

\begin{abstract}
Background: Campylobacter species are a leading cause of most important food-borne diarrhoeal illness worldwide while, poultry has been identified as a significant cause of Campylobacter infection in humans. C. jejuni is highly effective in colonizing chicken intestinal mucosa without causing any clinical manifestations and the consumption of poultry meat is the major source of transmission of bacteria to humans.

Methods: The total of 19 chicken meat samples collected from retail markets in Chennai were screened by cultural examination, further subjected to phenotypic characterization using biochemical test and genotypic characterization using polymerase chain reaction assay targeting hip $O$ and map $A$ genes.

Result: All the isolates showed growth on modified blood free charcoal cefoperazone deoxycholate agar media (mCCDA) and 18 $(94.73 \%)$ samples showed typical morphological characteristics. The $12(63.15 \%)$ isolates showed biochemical reactions positive. The results from polymerase chain reaction showed that $10(83.33 \%)$ isolates were positive for $C$. jejuni. This study suggested that, it is essential to investigate the incidence of Campylobacter jejuni infection in poultry and the risk factors at all production stages of meat production to help reducing the disease in humans in terms of food safety.
\end{abstract}

Key words: CCDA, C. jejuni, hip O, Hippurate, map A.

\section{INTRODUCTION}

Campylobacter is considered as a principal cause of most important zoonotic food-borne disease in humans for approximately 166 million diarrheal cases and 37,600 deaths per year globally (Oh et al., 2018). Campylobacter is 1 of 4 key global causes of diarrheal diseases of human gastroenteritis in the world (WHO, 2018). C. jejuni has been found to be the predominant species isolated from poultry samples and responsible for the majority of human Campylobacteriosis (Natsos et al., 2019). Poultry and poultry products are considered as the most important sources of human infections. Campylobacter jejuni is main foodborne pathogens and broiler meat is considered as the most important source of human Campylobacteriosis (Duque et al., 2021). The proliferation of $C$. jejuni in broilers suggests that the feed formulated to promote avian growth provides the nutrients required by these bacteria (Greene et al., 2020).

In humans, clinical signs of Campylobacteriosis include diarrhea, abdominal pain, fever, headache, nausea and vomiting. The main recognized sequelae are Guillain-Barré Syndrome (GBS), the Reactive Arthritis (REA) and irritable bowel syndrome (IBS). Thermo tolerant Campylobacter which has a clinical significance are $C$. jejuni and its represents more than $90 \%$ of human infections (Mikulic et al., 2016).

Campylobacter jejuni showed multiple drug resistance against some antibiotics, which is of public health concern and may pose serious problems in the treatment of animals (Shekhar et al., 2010). The control of Campylobacter in poultry seems crucial for the reduction of human
Department of Animal Biotechnology, Madras Veterinary College, Tamil Nadu Veterinary and Animal Sciences University, Chennai600 007, Tamil Nadu, India.

Corresponding Author: Sumedha Bobade, Department of Animal Biotechnology, Madras Veterinary College, Tamil Nadu Veterinary and Animal Sciences University, Chennai-600 007, Tamil Nadu, India. Email: sumedha_bobade@rediffmail.com

How to cite this article: Bobade, S., Vijayarani, K., Tirumurugaan, K.G., Thangavelu, A. and Vairamuthu, S. (2022). Morphological, Biochemical and Genotypic Analysis of Zoonotic Campylobacter jejuni Isolated from Chicken Meat Samples. Indian Journal of Animal Research. DOI: 10.18805/IJAR.B-4497.

Submitted: $26-04-2021 \quad$ Accepted: 30-10-2021

Online: 07-01-2022

Campylobacteriosis cases (Natsos et al., 2016). Hence this study was attempted to detect the presence of $C$. jejuniusing cultural, biochemical and PCR technique and compare these techniques for detection among raw chicken meat samples.

\section{MATERIALS AND METHODS}

\section{Collection of samples}

The present study was conducted at Department of Animal Biotechnology, Madras Veterinary College, Chennai, Tamil Nadu in the year 2018-19. A total of 19 samples comprising raw chicken meat were collected from retail markets around Chennai. All the samples were collected using sterile containers and transported immediately to the laboratory under cold conditions for microbiological analysis. 


\section{Processing of samples}

The isolation was performed according to Man (2011) and the isolates were identified by biochemical tests as described by (Fitzgerald and Nachamkin, 2007; Lastovica and Allos, 2008).

\section{Phenotypic characterization \\ Cultural examination}

Sample was enriched in modified Charcoal Cefoperazone Deoxycholate (mCCDA) broth (Hutchinson and Bolton, 1984) with CCDA supplement under microaerophillic conditions (candle jar method) by using internal gas generation system using (Microaerophilic gas pack CampyPack-BD oxoid).

\section{Biochemical test}

The isolates were identified as $C$. jejuni based on their morphological and biochemical tests. Suspected colonies were sub-cultured and confirmed by catalase, oxidase, nitrate and hippurate hydrolysis, Ninhydrin test, $\mathrm{H}_{2} \mathrm{~S}$ production.

\section{Molecular confirmation of Campylobacter jejuni}

The biochemically confirmed isolates employed for molecular confirmation as $C$. jejuni by polymerase chain reaction amplifying specific target gene. DNA were extracted by Phenol-Chloroform extraction method and the DNA concentration was quantified by nanodrop and stored at $-20^{\circ} \mathrm{C}$ until further processing.

Genotypic confirmation of isolates by polymerase chain reaction for hip $O$ gene and map $A$ gene

The isolates were confirmed by PCR using designed primers in the study as forward primer (5-TTCCATGACCACCTC TTCC-3) and reverse primer (5-CTACTTCTTTATTGCTT GCTGC-3) for hip O gene. The primers used for amplification of map A gene were forward primer (5-CTATTTTATTTTT GAGTGCTTGTG-3) and reverse primers (5-GCTTT ATTTGCCA TTTGTTTTATTA-3) (Khoshbakht et al., 2015).
The PCR reactions were performed in $25 \mu \mathrm{l}$ reaction mixture. The amplification conditions consisted of initial denaturation at $94^{\circ} \mathrm{C}$ for $3 \mathrm{~min}, 35$ cycles with denaturation at $94^{\circ} \mathrm{C}$ for $1 \mathrm{~min}$, annealing at $53^{\circ} \mathrm{C}$ for hip $01 \mathrm{~min}$, at $72^{\circ} \mathrm{C}$ for $1 \mathrm{~min}$, followed by a final extension at $72^{\circ} \mathrm{C}$ for 5 min respectively (Al-Amri et al., 2007). The annealing temperature for Map A gene was optimized as $52^{\circ} \mathrm{C}$ for 1 min (Khoshbakht et al., 2015). The DNA from C. jejuni (ATCC 3329) was included as positive control for PCR identification of the isolates. The amplified products were observed and photographed using gel documentation System (Applied Biosystems).

\section{RESULTS AND DISCUSSION}

Campylobacteriosis is one of the most common bacterial infections worldwide causing economic costs (Soro et al., 2020). Modified blood free Charcoal cefoperazone deoxycholate agar is commonly used worldwide (Hutchinson and Bolton, 1984). In current study a total of 19 samples were processed for isolation of Campylobacter, all samples showed growth on mCCDA agar plates. The isolates showed typical grey/white or creamy grey in colour and moist spreading type colonies with sticky nature were confirmed phenotypically as Campylobacter. The suspected colonies were examined for morphological characteristics, motility, Gram's staining. Campylobacter species are Gram negative rods with characteristically curved, spiral, or S-shaped cells. The overall incidence of Campylobacter was found to be 18 $(94.73 \%)$ by cultural examination.

\section{Biochemical characterization}

The isolates were processed for phenotypic characterization and identified by biochemical tests. The test for hippurate hydrolysis is critical for separation of Campylobacter jejuni and $C$. coli strains. Glycine and benzoic acid are formed when hippurate is hydrolysed by $C$. jejuni (Morris et al., 1985). Twelve $(63.15 \%)$ isolates were positive for catalase, oxidase, nitrate and hippurate hydrolysis, Ninhydrin test (Fig 1).

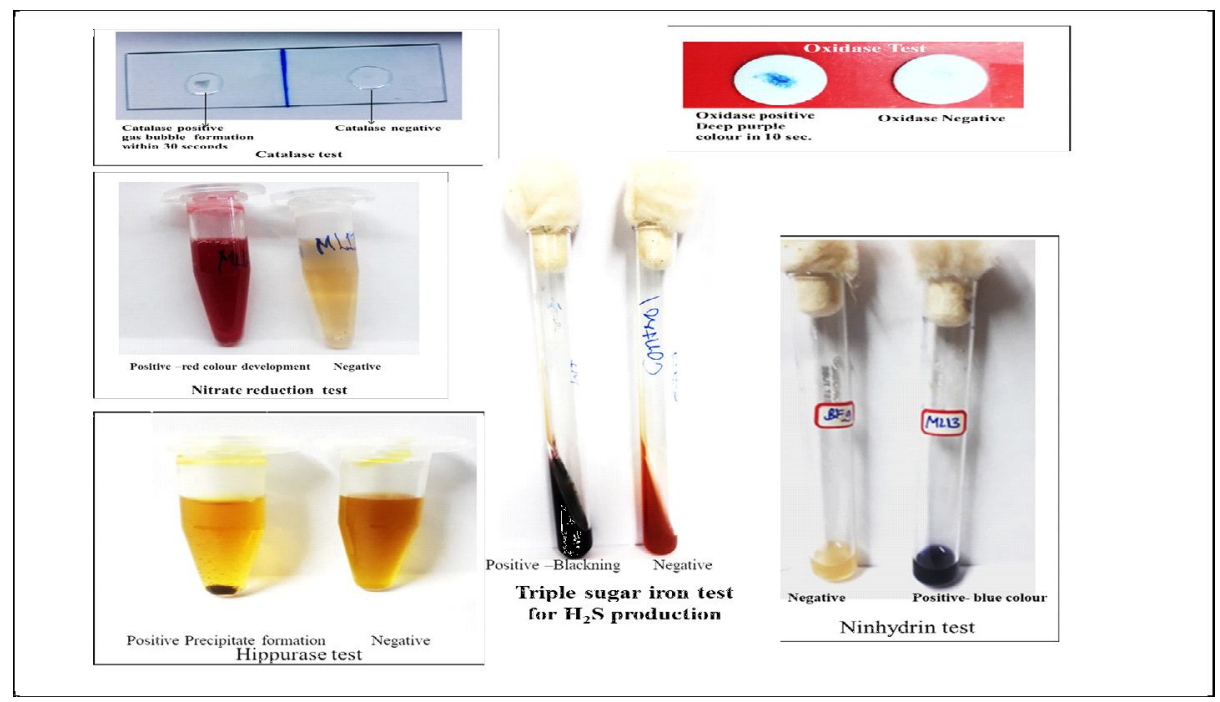

Fig 1: Characterization of $C$. jejuni isolates by biochemical tests. 
The samples from raw chicken meat (9) were positive for $\mathrm{H}_{2} \mathrm{~S}$ production. C. jejuni biotype 2 strains are $\mathrm{H}_{2} \mathrm{~S}$ positive, whereas $C$. jejuni biotype 1 strains are $\mathrm{H}_{2} \mathrm{~S}$ negative (Penner, 1988). In this study nine isolates belong to biotyope 2 while three belong to biotype 1 of $C$. jejuni. All the samples found to be positive for ninhydrin test confirmed as $C$. jejuni. Malik et al., 2014 studied hundre sis test positive for two isolates, categorized as $C$. jejuni a nd negative for 30 isolates while twelve $(63.15 \%)$ isolates were positive in this study.

\section{Genotypic characterization}

The size of PCR product for hip O gene was $270 \mathrm{bp}$ and the size of the PCR product for map A gene was 589 bp (Fig 2). The incidence of $C$. jejuni from raw chicken meat using three screening tests was given in Table 1, Fig 3. The total of 10 $(83.33 \%)$ isolates were confirmed as $C$. jejuni.

Campylobacterwas detected in $76 \%$ and Campylobacter jejuni was the most prevalent species (64.7\%) being contaminated from broiler meat products collected in retail outlets (Nicodeme et al., 2015). The prevalence of Campylobacterspp. in chicken meat was $17.33 \%$ and twenty three Campylobacter jejuni were identified by biochemical examination and confirmed by polymerase chain reaction collected from retail meat markets, slaughter houses (Moudgil and Kumar, 2014). In the present study higher incidence rate of $12(63.15 \%)$ was confirmed by biochemical tests and $10(83.33 \%)$ by polymerase chain reaction.
Sixty eight $C$. jejuni isolates were obtained with an overall prevalence rate of $34 \%$ using the uniplex PCR targeting map $A$ from different farms at Dakahlia Governorate in Egypt. (Younis et al., 2018). The isolates were confirmed as $C$. jejuni biochemically targeting the map $A$ gene of C. jejuni. A total of $17 \%$ and $11.87 \%$ of broiler chicken and layer chicken samples respectively, were positive for $C$. jejuni collected in Egypt (Ghoneim et al., 2020). While in the present study $12(63.15 \%)$ chicken meat samples were positive on the basis of biochemical testes and $10(83.33 \%)$ by PCR targeting map A gene and hip O genes. Chicken samples were bacteriologically positive for Campylobacter isolates and 285 isolates $(94.37 \%)$ were identified as C. jejuni by polymerase chain reaction targeting the hip O gene specific for C. jejuni (Barakat et al., 2020).

Campylobacter jejuni $(88.1 \%)$ was most prevalent species isolated from broiler meat samples by cultural method and polymerase chain reaction assay (Zendehbad et al., 2015). Four C. jejuni (3.3\%) isolated from poultry meat in Northern Poland (Szczepanska et al., 2017), while higher incidence $(63.15 \%)$ was found in our study. Campylobacter jejuni $(58.82 \%)$ was isolated from raw meat samples in Kolkata, India suggested that the consumption of undercooked meat possess a possible health risk for consumers (Sharma et al., 2016).

The most predominantly isolated species among Campylobacter was C. jejuni $(69.5 \%)$ from chickens

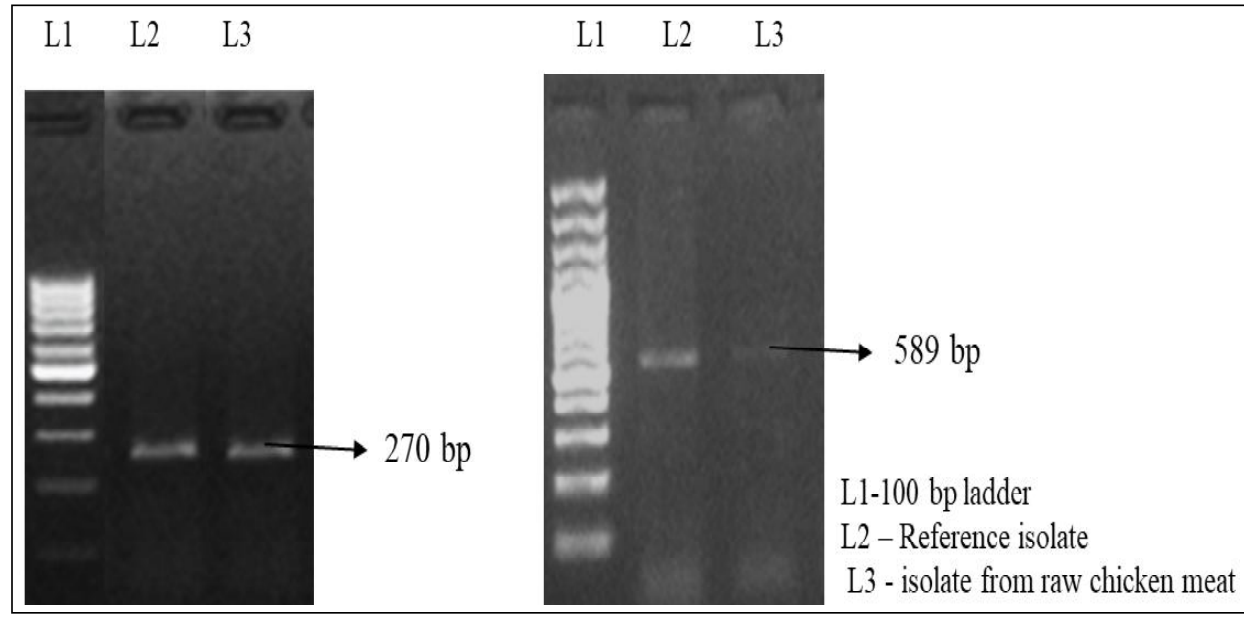

Fig 2: Agarose gel showing the amplification product of hip $O$ and map A gene of Campylobacter jejuni (270 bp and 589 bp) ( $L=100$ bp DNA ladder).

Table 1: Result of cultural, phenotypic and genotypic characterization of $C$. jejuni isolates.

\begin{tabular}{|c|c|c|c|c|}
\hline \multicolumn{4}{|l|}{ Test characteristics } & \multirow{2}{*}{$\begin{array}{c}\text { Results } \\
18(94.73 \%)\end{array}$} \\
\hline Cultural examination & & & & \\
\hline \multirow[t]{7}{*}{ Phenotypic characterization } & Biochemical test & Catalse & & $12(63.15 \%)$ \\
\hline & & Oxidase & & $12(63.15 \%)$ \\
\hline & & Nitrate & & $12(63.15 \%)$ \\
\hline & & Hippurate hydrolysis & & $12(63.15 \%)$ \\
\hline & & Ninhydrin & & $12(63.15 \%)$ \\
\hline & & $\mathrm{H}_{2} \mathrm{~S}$ production & Positive & $9(47.36 \%)$ \\
\hline & & & Negative & $3(15.78 \%)$ \\
\hline Genotypic characterization & & & & $10(83.33 \%)$ \\
\hline
\end{tabular}




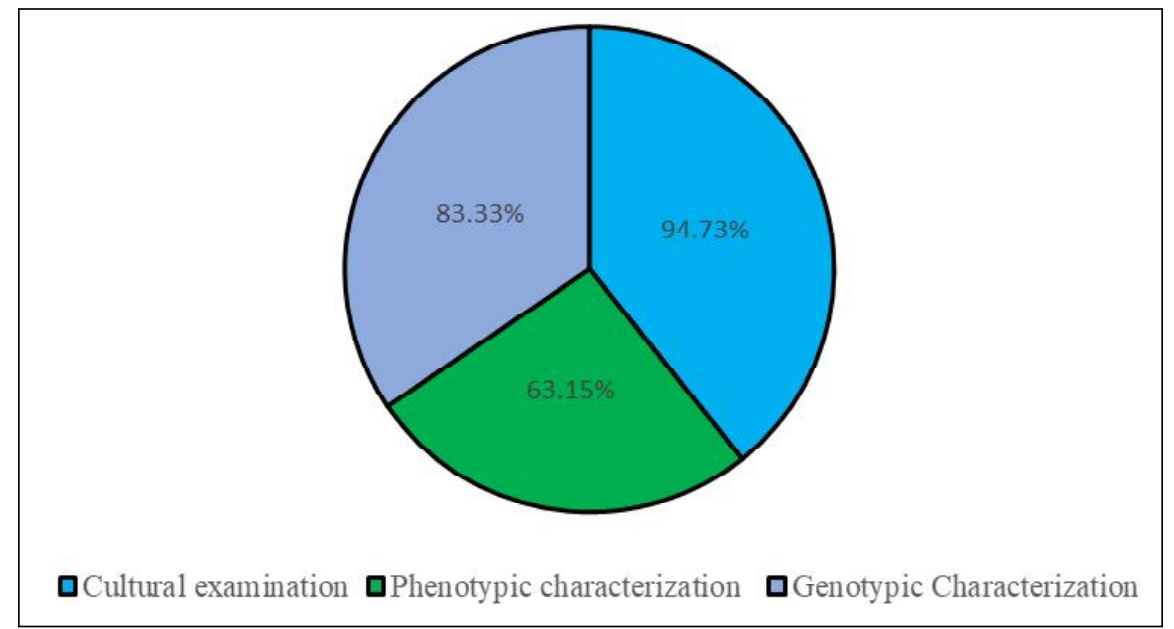

Fig 3: Comparative result of phenotypic and genotypic study of $C$. jejuni from raw chicken meat samples.

(Sinulingga et al., 2019). A total of $17 \%$ and $11.87 \%$ of broiler chicken and layer chicken samples respectively were positive for $C$. jejuni as the most commonly isolated species (Frosth et al., 2020). The risk of Campylobacteriosis in chicken meat consumers in southern Benin was studies and reported prevalence of $C$. jejuni $(23.4 \%)$ from chicken meat by molecular methods (Kouglenou et al. 2020), while higher incidence $(83.33 \%)$ was reported in our study.

Campylobacter jejuni was recognized as a main species accounting for $37(68.5 \%)$ from chicken and turkey meat samples (Kanaan and Abdulwahid, 2019). The most frequently reported isolates were Campylobacter jejuni (22\%) in poultry raw meat samples sold in retails. This suggested that "One Health" approach represent a strategy to control Campylobacter spp. and further programmes, policies, legislations and research will contribute to control contamination at primary production level and retail outlet (Gigliotti et al., 2019). Campylobacter isolates (35.4\%) were recovered and analysed by multiplex PCR and four (13.8\%) were identified as $C$. jejuni from broiler meat samples (Nafarrate et al., 2020) and their results concur with the results of our study.

C. jejuni was isolated from $17.0 \%$ of samples obtained in butcher shops and formal slaughter houses (Alaboudi et al., 2020). C. jejuni was isolated in $5(41.7 \%)$ raw chicken samples collected from local market (Chen et al., 2020). Baali et al. (2020) reported that $65 \%, 55 \%$ and $70 \%$ of the cloacal swab, neck skin and caecal content were contaminated with thermotolerant Campylobacter strain, Campylobacter jejuni was the predominant species (73.5\%) from broiler chickens in Batna, East Algeria and this is in accordance with the results of our study.

\section{CONCLUSION}

Poultry is an important reservoir and source of human Campylobacteriosis, although the contribution of other sources, reservoirs and transmission in reducing contamination of other meat samples. Campylobacter colonization in poultry and focus at the farm level has been successful in intervention strategies reducing the number of Campylobacter cases in several countries. Increasing farm biosecurity and education of consumers are likely to limit the risk of infection. Active on-farm biosecurity measures on chicken farms and more hygienic efforts in slaughter houses, in local chicken slaughter shops should be made for the effective control of these foodborne pathogens.

\section{ACKNOWLEDGEMENT}

The authors wish to sincerely thank the Tamil Nadu Veterinary and Animal Sciences University, Department of Animal Biotechnology, Madras Veterinary College, Chennai. All authors contributed to the study.

\section{Conflict of interest}

The authors declare that they have no conflict of interest.

\section{REFERENCES}

Al Amri, A., Senok, A.C., Ismaeel, A.Y., Al-Mahmeed, A.E., Botta, G.A. (2007). Multiplex PCR for direct identification of Campylobacter spp. in human and chicken stools. Journal of Medical Microbiology. 56: 1350-1355.

Alaboudi, A. R., Malkawia, I. M., Osailib, T. M., Abu-Bashae, E.A. and Guitiand, J. (2020). Prevalence, antibiotic resistance and genotypes of Campylobacter jejuni and Campylobacter coli isolated from chickens in Irbid governorate, Jordan. International Journal of Food Microbiology. 327: 108-656

Baali, M., Lounis, M., Al Amir, H.L., Ayachi, A. Hakem, A. and KassahLaouar, A. (2020). Prevalence, seasonality and antimicrobial resistance of thermo tolerant Campylobacter isolated from broiler farms and slaughter houses in East Algeria. Veterinary World. 13: 1221-1228.

Barakat, A.M.A., Abd El-Razik, K.A., Elfadaly, H.A., Rabie, N.S., Sadek, S.A.S. and Almuzaini, A.M. (2020). Prevalence, molecular etection and virulence gene profiles of Campylobacter species in human and foods of animal origin. Veterinary World.13: 1430-1438. 
Chen, H., Dai, Y., Chen, J., Zhang, Y., Zhan, L., Mei, L. and Wang, H. (2020). Epidemiological and whole genomic sequencing analysis of a Campylobacter jejuni outbreak in Zhejiang Province, China, May 2019. Foodborne Pathogens and Disease. 17(12): 1-7.

Duque, B., Canon, J., Haddad, N., Guillou, S. and Membre, J. (2021). Quantitative approach to assess the compliance to a performance objective (PO) of Campylobacter jejuni in poultry meat in France. International Journal of Food Microbiology. 336: 108-916.

Fitzgerald, C. and Nachamkin, I. (2007). Campylobacter and Arcobacter. In: Manual of Clinical Microbiology, [P.R. Murray, E.J. Baron, J.H. Jorgensen, M.L. Landry and M.A. Pfaller (ed.)], $9^{\text {th }}$ ed. ASM Press, Washington, DC. 933-946.

Frosth, S., Karlsson-Lindsjo, O., Niazi, A., Fernstrom, L.L. and Hansson, I. (2020). Identification of transmission routes of Campylobacter and on farm measures to reduce Campylobacter in chicken. Pathogens. 9: 1-17.

Ghoneim, N.H., Abdel-Moein, K.A., Barakat, A.M.A., Hegazi,A.G., El-Hamid, K.A., El-Razik, A. and Sadek, S.A. (2020). Isolation and molecular characterization of Campylobacter jejuni from chicken and human stool samples in Egypt. Food Science and Technology. 1-8.

Gigliotti, D., Bianchi, M.D., Galleggiante, C.A, Barbaro, A., Adriano, D., Traversa, A., Cravero, D. and Decastelli, L. (2019). Prevalence and characterization of Campylobacter spp. in poultry meat: Results of a year surveillance in the North-West of Italy. EC Microbiology. 15(12): 136-142.

Greene, G., Koolman, L., Whyte, P., Lynch, H., Coffey, A., Lucey, B., Egan, J., O'Connor, L. and Bolton, D. (2020). An in vitro investigation of the survival and/or growth of Campylobacter jejuni in broiler digestate from different feed types. Letters in Applied Microbiology. 72: 36-40.

Hutchinson, D.N. and Bolton, F.J. (1984). Improved blood-free selective medium for the isolation of Campylobacter jejuni from fecal specimens. Journal of Clinical Pathology. 37: 956-957.

Kanaan, M. and Abdulwahid, M.T. (2019). Prevalence rate, antibiotic resistance and biotyping of thermotolerant Campylobacter isolated from poultry products vended in wasit markets. Current Research in Nutrition and Food Science. 7(3): 905-917.

Khoshbakht, R., Tabatabaei, M., Hosseinzadeh, S., Aski, H.S. and Seifi, S. (2015). Genetic characterization of Campylobacter jejuni and $C$. coli isolated from broilers using flaA PCRrestriction fragment length polymorphism method in Shiraz, Southern Iran. Jundishapur Journal of Microbiology. 8: e18573.

Kouglenou, S.D., Agbankpe, A.J., Dougnon, V., Djeuda, A.D., Deguenon, E., Hidjo, M., Moussa, L.B. and Bankole, H. (2020). Prevalence and susceptibility to antibiotics from Campylobacter jejuni and Campylobacter coli isolated from chicken meat in Southern Benin, West Africa. BMC Research Notes. 13(305): 1-6.

Lastovica, A.J. and Allos, M.B. (2008). Clinical Significance of Campylobacter and Related Species other than Campylobacter jejuni and Campylobacter coli. In: Campylobacter, $3^{\text {rd }}$ edn, eds. [Nachamkin, I., Szymanski, C.M., Blaser, M.J.] Washington, D.C.: American Society for Microbiology.123-50.
Malik, H., Ashok Kumar, Rajagunalan, S., Kataria, J.L., Anjay and Sachan, S. (2014). Prevalence of jejuni and Campylobacter coli among broilers in Bareilly region. Veterinary World. 7(10): 784-787.

Man, S.M. (2011). The clinical importance of emerging Campylobacter species. Nat. Rev. Gastroenterol. Hepato. 8: 669-685.

Mikulic, M., Humski, A., Njari, B., Ostovic, M., Duvnjak, S. and Cvetnic, Z. (2016). Prevalence of thermotolerant Campylobacter spp. in chicken meat in croatia and multi locus sequence typing of a small subset of Campylobacter jejuni and Campylobacter coli isolates. Food Technology and Biotechnology. 54: 475-481.

Morris, G.K., Sherbeeny, M.R., Patton, C.M., Kodaka, H., Lombard, G.L.,Edmonds,P., Hollis D.G. and Brenner, D.J. (1985). Comparison of four hippurate hydrolysis methods for identification of thermophilic Campylobacter spp. Journal of Clinical Microbiology. 22: 714-718.

Moudgil, P. and Kumar, A. (2014). Prevalence and antibiotic resistance pattern of Campylobacter species in foods of animal origin. Veterinary World. 7(9): 681-684.

Nafarrate, I., Lasagabastera, A., Sevillanob, E. and Mateob, E. (2020). Prevalence, molecular typing and antimicrobial susceptibility of Campylobacter spp. isolates in northern Spain. Journal of Applied Microbiology. 130(4): 13681379.

Natsos, G., Koutoulis, K.C., Sossidou, E., Chemaly, M. and Mouttotou, N.K. (2016). Campylobacter spp. infection in humans and poultry. Journal of the Hellenic Veterinary Medical Society. 67: 65-82

Natsos, G., Mouttotou, N., Ahmad, S., Kamran, Z., Ioannidis, A. and Koutoulis, K. (2019). The genus Campylobacter: detection and isolation methods, species identification and typing techniques. Journal of the Hellenic Veterinary Medical Society. 70: 1327-1338.

Nicodeme, M.G., Rivoal, K., Houard,E. , Rose, V., Quesne,S., Mourand, G., Rouxel, S. , Kempf, I., Guillier, L., Gauchard F. and Chemaly, M. (2015). Prevalence and characterization of Campylobacter jejuni from chicken meat sold in French retail outlets. International Journal of Food Microbiology. 203: 8-14.

Oh E., Katelyn andrews, J. and Jeon, B. (2018). Enhanced biofilm formation by ferrous and ferric iron through oxidative stress in Campylobacter jejuni. Frontiers in Microbiology. 9(1204): 1-9.

Penner, J.L. (1988). The Genus Campylobacter: A Decade of progress. Clinical Microbiology Reviews. 1: 157-172.

Sharma, K., Chattopadhyay, U. K. and Naskar, K. (2016). Prevalence of Campylobacter species in raw meat samples sold in open markets of Kolkata city. International Journal of Agriculture Environment and Biotechnology. 9(4): 5-35.

Shekhar, C., Motina, E. and Kumar, S., (2010). Microbiological quality of raw milk and its public health significance. Journal of Dairying, Foods and Home Sciences. 29 (1): 15-18.

Sinulingga, T.S., Aziz, S.A., Bitrus, A.A., Zunita, Z. and Abu, J. (2019). Occurrence of Campylobacter species from broiler chickens and chicken meat in Malaysia. Tropical Animal Health and Production. 52: 151-157. 
Morphological, Biochemical and Genotypic Analysis of Zoonotic Campylobacter jejuni Isolated from Chicken Meat Samples

Soro, A.B., Whyte, P., Bolton, D.J. and Tiwari, B.K. (2020). Strategies and novel technologies to control Campylobacter in the poultry chain: A review. Comprehensive Reviews in Food Science and Food Safety. 19: 1353-1377.

Szczepanska, B. andrzejewska, M., Spica D., Klawe, J.J. (2017). Prevalence and antimicrobial resistance of Campylobacter jejuni and Campylobacter coli isolated from children and environmental sources in urban and suburban areas. BMC Microbiology. 17(80): 1-9.
WHO (2018). https://www.who.int/news-room/fact-sheets/detail/ Campylobacter, 1-5.

Younis, G., Awad, A. and Khairy, M. (2018). Molecular Characterization and virulence of Campylobacter jejuni isolated from broiler chickens. International Journal of Poultry Science. 17: 499-506.

Zendehbad B., Khayatzadeh, J. and Alipour, A. (2015). Prevalence, seasonality and antibiotic susceptibility of Campylobacter spp. isolates of retail broiler meat in Iran. Food Control. 53: $41-45$. 